\title{
The Achievements and Contributions of Domiciano K. Villaluz: A Renowned Founder on the Artificial Culture of Penaeus Monodon Fabricius
}

\author{
Assistant Professor Desheree Judena Gayo - Preciado \\ Department of Social Sciences and Humanities \\ College of Education and Social Sciences \\ Mindanao State University at Naawan
}

\begin{abstract}
This is a qualitative study employing historical-descriptive methods of research. Key informant interview and documentary analysis were used to gather pertinent data. Significantly, this paper is an attempt to present the historical narratives on achievements and contributions of Domiciano K. Villaluz in Mindanao State University as the Father of Fisheries Education. This paper highlights his leadership. DK Villaluz made a breakthrough in producing the sugpo fry through artificial culture with the help of a hatchery and larval feeding techniques under laboratory conditions. It was the first documented successful experiment. His laudable achievements revolutionized an impact to the aquatic industry. Most importantly, he leaves a contribution that spun the creation of another campus of Mindanao State University System- the Mindanao State University at Naawan which at present a premier institution in marine biological sciences and fisheries education. This article closes with a call for a more critical approach to the leadership skills of DK Villaluz..
\end{abstract}

Keywords: DK Villaluz, historical narratives, fisheries education, aquatic industry

\section{Introduction}

The creation of a University is an important part of history. According to Ding, X. (2010), it is in University where basic research long term economic development and applied research can lead to useful applications. Albritton, T.J. (2012) providing a history of historically colleges and universities must include how and why they were founded, funding sources and needs over time. Keulen, S., and Kroeze, R. (2012) says organization studies requires a basic theoretical understanding of 'doing history' and an appreciation of the centrality of narrative in history. However, attempts to trace the historical and philosophical foundations of academic institution, great leaders can rise when there is a great need. Caryle (1841) mentioned that the history of what man has accomplished in this world, is at bottom the History of the Great Men who have worked here. They were the leaders of men, these great ones; the modellers, patterns, and in a wide sense creators. Mohammed, Raed, et al. (2018) added that organization needs a leader who can understand and handle the complexity of the world. Therefore, a leader should always improve the quality of knowledge related to leadership and implement it in the field where they contribute for. Also, Smith (1984) the sum of leaders in historical endeavors has relevance for contemporary research and its problems. Hence, Post, J. (Ed.). (2003) says that world affairs are powerfully driven by this personality.

The prominence of Mindanao State University at Naawan as a premier institution for marine biological sciences and aquaculture education in Southern Philippines began with a man who had a strong desire for research activities. This scholar excelled in many fields of endeavors both in academe and fishery industry. He was a research scientist, a fishery expert, an educator and environmentalist.

\subsection{Objectives of the study}

This paper presents the achievements and contributions of Domiciano K. Villaluz to the national fisheries education and aquatic industry by interpreting narratives and primary documents. This study infers that DK Villaluz's efforts and expertise in leadership and research has made known the Mindanao State University at Naawan Campus in the areas of marine biological sciences and aquaculture education. It is important to determine and describe his family, education, qualifications and career to gain better under understanding of his achievements and contributions. This study is not a complete historical narratives of DK Villaluz in terms of his achievements and contributions. Significantly, it tries to present highlights on his achievements and contributions only during his stay in the University and his contributions to the creation of Mindanao State University at Naawan.

\section{Methodology}

This is a qualitative study employing historical-descriptive methods of research. Using purposive sampling, the researcher selected former and present employees of Mindanao State University whose age are (50) years old and up as potential informants to generate pertinent data. 
They were with Domiciano K. Villaluz when he was the Dean of the College of Fisheries in Marawi City and Director of Mindanao State University-Institute of Fisheries and Development in Naawan. They had the first hand interactions with him. The researcher made frequent visits to Mindanao State University -Marawi College of Fisheries, Mindanao State University at Naawan Offices such as: Library, Institute of Fisheries Research and Development, Fisheries Technology Resource Center Office, Office of the Chancellor, Administration Office, Physical Plant, School of Marine Fisheries Technology, Ancestral House of DK Villaluz in Naawan and informant's residences or offices. Following the basic procedures in conducting research, the researcher forwarded a communication to the respondents to conduct an interview. Having granted the permission, the researcher set a date for the interview.

The researcher also employed documentary analysis such personal records of Domiciano K. Villauz, Mindanao State University Board of Regents Resolutions, Mindanao State University Annual Reports, Technical Reports, Programs, and Lectures. Books, magazines, journals, theses from MSU at Naawan, and electronic sources were also utilized to supplement the data.

\section{Discussion}

\subsection{Family, Education, Qualifications and Career of Domiciano K. Villaluz}

Domiciano Kapili Villaluz was the youngest child of the late Felix Villaluz and Paula Kapili. He was born on July 30, 1909 at Angono, Rizal. His father was a farmer and at the same times an administrator of the Villaluz family farm. His grandfather was the Tenientedel Barrio of Angono during the Spanish regime (D.K. Villauz: Memorial Lecture Series in Aquaculture and Fisheries, September 11968 to August 31, 1987, Institute of Fisheries Research and Development, Naawan, Misamis Oriental).

He grew up in a serene and placid rural area of Binangonan, Angono, Rizal. As a child, he frequently visited Laguna de Bay. At that time Laguna de Bay was rich and abundant in fauna and flora species. His early contacts and observations of the Laguna de Bay developed in him a keen interest towards aquatic life (D.K. Villauz: Memorial Lecture Series in Aquaculture and Fisheries, September 1, 1968 to August 31, 1987, Institute of Fisheries Research and Development, Naawan, Misamis Orietal).

He dreamt of becoming a physician that is why he pursued Bachelor of Science in Education major in Zoology at the University of the Philippines in 1931. In the same University, he finished his Master of Science in Zoology in 1937. From 1939 to 1941, he was a scholar of the Commonwealth of the Philippines at the Imperial Fisheries Institute of Tokyo, Japan. By chance, he was given an opportunity to pursue Master's degree in Fisheries at the United States State Department in the University of Washington from 1946 to 1947 where he finished with Honors (Personal Record. Domitian K. Villous. Villous Ancestral House. Naawan, Misaims Oriental, Retrieved on May 12, 2009).

On September 12, 1937, he became a Junior Fishery Technologist. In the following year, on April 2, he took up the Fishery Technology Examination followed by Pension ado Fisheries Examination on July 30. On February 11, 1961, he took the Loan Evaluator Examination (Personal Record. Domitian K. Villous. Villous Ancestral House. Naawan, Misamis Oriental, Retrieved on May 12, 2009).After he finished his college, he worked as an Assistant Instructor in the Zoology Department, College of Liberal Arts at the University of the Philippines. He also worked as part-time Instructor in Biology and Botany at San Beda College, Manila. This was the beginning of his career as fishery expert, educator, and environmentalist (Aldon, M.T. 2018. Dean Domitian K. Villaluz as the First AQD Chief. Newsletter of the SEAFDEC Aquaculture Department. Tigbauan, Ilo-Ilo, Philippines, p.4).

From 1946 to 1948, he worked in Bureau of Fisheries as Assistant Ichthyologist where he assisted the Philippine Institute of Fisheries and Research in conducting researches. This endeavor was continued when he transferred at Rehabilitation Finance Corporation where he worked as a researcher from July 1, 1948 to September 1, 1952. However, on September 4, 1952 until June 25, 1956 he became Fishpond Supervisor in the same company where he administers fishpond financing and Agricultural Projects. He also worked as Agricultural Supervisor at the Development Bank of the Philippines as Agricultural Supervisor from June 25, 1956 to February 28, 1961. From December 14, 1962 to June 1963 he served in the Bureau of Fisheries under the Office of the President as Fisheries Consultant for the P15 million Fishery Projects (Personal Record. Domiciano K. Villaluz. Villaluz Ancestral House. Naawan, Misamis Oriental. Retrieved on May 12, 2009).

His strong academic records and enumerable experiences develop his passion and love for research activities. He wrote number of research studies of which one of it was Oyster Farming. His article was published in the Philippine Journal of Science in 1938. This research was instrumental in the establishment of an Oyster Farm at Binakayan, Cavite. With this research, he introduced the first hanging method of oyster farming in the Philippines which led to the development of a large-scale commercial oyster farming in the country (D.K. Villauz: Memorial 
Lecture Series in Aquaculture and Fisheries, September 11968 to August 31, 1987, Institute of Fisheries Research and Development, Naawan,MisamisOrietal).

He also wrote The Cultivation of Sugpo (Penaeusmonodon Fabricius) in the Philippines along with Dr. Deogracias Villadolid. Their research work was published in Philippine Journal of Fisheries, Vol.1 No.1 pp. 69-78 in 1951 ((Personal Record. Domiciano K. Villaluz. Villaluz Ancestral House.Naawan, Misamis Oriental. Retrieved on May 12, 2009). They described the morphological structure of sugpo (including the feeding habits of sugpo, migration of sugpo fry, sugrpo fry fishery, preparation of sugpo fry nursery, stocking sugpo fry in the nursery, care of the sugpo fry, and preparation of the sugpo rearing pond. (D.V., Villadolid and D.K., Villaluz. (1951). The Cultivation of Sugpo (Penaeusmonodon Fabricius) in the Philippines. Philippine Journal of Fisheries, Vol.1, No.1, pp. 70-76).

According to his personal record, he had published twenty-one scientific papers. He also authored a book entitled "Fish Farming in the Philippines" in 1953. This was being used as textbook in Fish Culture Courses, College of Fisheries, and University of the Philippines and as reference in Fish Culture in all fisheries schools under the Bureau of Public Schools.

When he opt to retire on February 28, 1963 under Republic Act No.1616, his expertise still sought by top universities. One of which was the University of Mindanao (UM), the former name of Mindano State University, at Marawi City, Lanao Del Sur. It was on December 17, 1962 that UM President Antonio Isidro invited DK Villaluz to join the University's teaching force. On March 27, 1963, DK. Villaluz positively responded to the invitation. On April 23, 1963, UM President Antonio Isidro interviewed DK. Villaluz and on June 6, 1963, DK Villaluz joined UM and was awarded an item and earned a salary of P6, 000.00. On February 1, 1965, DK Villlaluz then enjoyed a salary of P10, 620.00 per annum as Professor III (Personal Record. Domiciano K. Villaluz. Villaluz Ancestral House.Naawan, Misamis Oriental. Retrieved on May 12, 2009).

\subsection{Achievements in Mindanao State University}

As a faculty, DK Villaluz was tasked to perform the following duties: 1. Help in the organization of the college. 2. Prepare the list of fisheries courses and the preparation of the Curriculum. 3. Give lectures on fisheries and allied courses. 4. Conduct researches and wrote technical reports and; 5. Help the management in fisheries projects because that time the University has just started its class opening on June 13, 1962 (Letter of Invitation to Domiciano K. VIllaluz from Dr. Antonio Isidro. Villaluz, University of Mindanao. Marawi, Lanao Del Norte. December 17, 1962; and Statement of Duties. Salvador Mariño. Executive Secretary. Office of the President. June 11, 1963. Manila).

On August 26, 1964, he became the Acting Dean of the College of Fisheries, DK Villaluz's interests in aquatic life prompted to look for a field laboratory for brackish water aquaculture studies in order to complement the Mindanao State University aquaculture program ("MSU Naaawan". Annual Report 1999. NaawanMisamis Oriental. 1999. pp.2-3.). One informant said they scouted several places in Lanao Del Norte and Misamis Oriental but they picked Naawanwhich is quiet and serene place. This place is very ideal for laboratory activities and accessible as well.

Through the help of the municipal government of Nawan headed by Honorable Mayor GalicanoCosing, DKVillaluz and his team were able to negotiate a sizeable 15-hectare track of mangrove swamp which then served as a practicum site for the pioneering batch of Bachelor of Science in Fisheries students taking their courses in fishpond construction and fish cultivation. (Cuyno, Lieve L. and Requino, Annabelle B. "The History of Naawan, Misamis Oriental (1957-1999)". Unpublished thesis. Department of History. MSU-IIT. Iligan City. 2000).Another informant said there were about twenty students who helped in the construction. They only had trees for shelter at night. Dinner was usually shared over a can of sardine. The construction works of fishpond dikes was laborious and challenging.

The laboratory was named Mindanao State University Marine Fisheries Research Laboratory (MSU-MFRL) (Proposed Reorganization of MSU-Institute of Fisheries Research and Development into Marine Science Center. "The Institute". MSU-Institute of Research and Development. Naawan, Misamis Oriental 1979. p.2.). It became an extension classroom of the MSU-Marawi College of Fisheries and a prospect for culturing commercial species of fishes and crustaceans; and housing experimental fishponds and a pilot shrimp laboratory.

One experiment conducted in the field laboratory was the hatchery technique of producing the fry of sugpounder laboratory conditions. Sugpoa kind of shrimp known scientifically as PenaeusmonodonFabricius is cultivated on a commercial scale in Philippine estuarine fishponds either together with bangos, Chanoschanos or separately by itself. Considered a table delicacy, sugpo commands the highest price among the shrimps being sold in the local markets. A kilo which generally contains from eight to twelve individual sugpo, measuring from six to ten inches long, costs as much as eight pesos. 
A hectare of fishpond on the average can produce around three hundred and fifty kilos of sugpo of marketable size after six months of cultivation (D.V. Villadolid and D.K. Villaluz, (1951).The Cultivation of Sugpo (PenaeusmonodonFabricius) in the Philippines, Philippine Journal of Fisheries, Vol.1. No.1, pp.69-78). The growing demand of sugpoboth in local and foreign markets, most fishpond owners in the Philippines are now starting to shift to sugpo culture. The price per kilogram in the local market is from P6.00 to P10.00, while in Japan (Tokyo Central Market), fresh prawns sell it from 7 to 30 U.S. dollars per kilogram. Japan alone imports around P92 million worth of shrimps every year. The United States and France may also be considered as potential markets for sugpo experts (D.K. Villaluz, et al., (1969) Reproduction, Larval Development, and Cultivation of Sugpo (PenaeusmonodonFabricius). Vol.98, Nos.3-4, September-December, p.205).

Hence, the value of this aquatic resource potentially spurs growth and development in the locality because no scientists had ever successfully completed its life cycle. In December 1969, DK Villaluz, along with other MSUMFRL researchers, made a breakthrough in aquaculture research on the spawning and larval development of sugpounder laboratory conditions. Results from experiments prove that hatching of eggs under controlled conditions insure much greater survival rate of fry in comparison to the natural conditions. With the help of a hatchery more than 10,000 sugpo fry have been produced from around 1.5 million eggs laid by a mother sugpo in the Mindanao State University Marine Research Laboratory (D.K. Villaluz, et.al, (1969) Reproduction, Larval Development, and Cultivation of Sugpo (PenaeusmonodonFabricius). Vol.98, Nos.3-4, September -December, pp. 206-207).

The Report of this breakthrough, entitled "Reproduction, Larval Development and Culture of Sugpo, PenaeusmonodonFabricius", was published in Philippine Journal of Science, Vol. 98, Nos. 3-4, SeptemberDecember 1969 as the first documented successful experiment. (Jamias, Juan F. "A Brief History of the MSUIFRD”. MSU-IRD Annual Report 1975. MSU-Institute of Fisheries Research and Development. Naawan, Misamis Oriental. 1975. p.144-145). DK success in prawn research convinced the National Science Development Board (NSDB) of the very bright prospect of shrimp culture in the country. The NSDB awarded DK AND A colleague in 1979 a three-year project on shrimp construction of a pilot laboratory (Aldon, M.T. 2018. Dean Domiciano K. Villaluz as the First AQD Chief. Newsletter of the SEAFDEC Aquaculture Department. Tigbauan, Ilo-Ilo, Philippines).

\section{Contributions to the Creation of Mindanao State University at Naawan}

\subsection{The Creation of Mindanao State University Institute of Fisheries Research and Development}

The study of DK Villaluz brought tremendous impact to the course of Mindanao State University Marine Fisheries Research Laboratory. On November 15, 1971, it became the research arm of the Mindanao State University Sulu College of Technology and Oceanography which served as the nucleus in conducting their research and study (Special Order 29, Series of 1971. Mindanao State University- Marawi. March 3, 1971. Signed by President MauyagTamano).

Since then, the erstwhile field laboratory became the Mindanao State University-Institute of Fisheries and Research Development (MSU-IFRD), a distinct unit of Mindanao State University. It was established as a distinct external unit of the University and charged with the function of spearheading the researches in the wider aspects of fisheries and brackish aquaculture. It also aimed for diversification and expansion in terms of research activities and programs to include technology transfer and manpower assistance as it is consequently envisioned to be the center for aquaculture research and development in Southern Philippines (MSU-Institute of Research and Development. D.K Villalluz Memorial Lecture Series in Aquaculture and Fisheries. (September 1, 1986 to August 31, 1987). Naawan, Misamis Oriental: 1987).

On December 4, 1973, Mindanao State University-Institute of Fisheries and Research Development became an academic unit directly under the Mindanao State University Office of the Vice President for Academic Affairs. The Institute was also assigned the management and supervision of the Naawan Fisheries High School. At that time also, the Institute program had the following components: 1) Research; 2) Training and Extension; 3) Academic; and 4.) Conservation mainly tasked to undertake research and extension projects (Jimenez, Jaime U. "About MSUNaawan". MSU-Naawan Annual Report 2003. Naawan, Misamis Oriental. 1993.p.2). With its mandate to undertake research the Institute has published several researches relating to marine biological sciences and aquaculture. This inspired many non-government and government organizations to finance their different research projects from 1973 to 1979.

Apart from production of scholarly papers, the Institute continued to expand its physical development as a respond to the increasing research activities at the Institute. The leadership of DK Villaluz unlock doors for greater opportunities to accomplish the following: constructions of the administration-laboratory building, the wet laboratory with three circular and twelve concrete hatchery tanks and a guest house for visiting scientists in October 
1972. In 1973, additional supporting works and equipment such as water pumps, the aeration system, and the lighting facilities were installed. From 1974 to 1975, the Institute has accomplished the following:

1. 15 hectares of swampland - around 6 hectares of which have been developed into bangus and prawn fishponds; 2. Approximately 12.5 hectares of land was appropriated for laboratory buildings, dormitories, staff housing and other installations needed for the development of the Institute;

3. Two-compartment experimental ponds with reinforced concrete sides, concrete gates and soil bottom were used as experimental nursery ponds;

4. Pilot laboratory with adjoining 2-bedroom living quarters for researchers, and an outside pilot hatchery with plastic sheet roofing was constructed in 1969;

5. Pilot power house equipped with generating unit and air compressor and powered by Peter diesel engine and a water pump was built;

6. Administration laboratory building, with a floor area of 1,677 square meters was constructed to house the following: (a) administrative offices; (b) conference room; (c) projection and lecture rooms; (d) library; (e) snack room; (f) chemistry laboratory; (g) biology laboratory; (h) instruments and chemical storage rooms; (i) visiting scientists laboratory; (j) general laboratory; (k) toilets, baths, locker rooms;

7. Wet laboratory and hatchery complex with a total floor area of 1,120 sq. meters were erected and contained the following: (a) 33 concrete circular hatching tanks each with 177 tons capacity ; (b) 4 concrete rectangular tanks each with 72 tons capacity; (c) 8 small concrete rectangular tanks each with 18 tons capacity; (d) 12 diatom culture tanks; (See Figure 3.7)

8. Guest house was built for visiting scientists and other MSU official guests, with a floor are of 308 sq. meters, and furnished with a 3 air conditioned bedrooms, caretaker's room, sala, dining room, kitchen, lanai and seaside veranda, and a toilet bath for each room;

9. A Plankton house was put up with a floor area of 564 sq. meters, and furnished with mechanically operated plastic roof that can be moved to admit direct sunlight into the 27 marine plywood diatom culture tanks. The house was used for the study and culture of diatoms as food of P. monodon larvae;

10. Post Pump house no. 2 was equipped with 4 water pumps and 4 electric motors while power house no. 2 equipped with 2 rooted blowers and 2 electric motors and 1 diesel engines;

11. Freshwater system consisting of deep well with $2 \mathrm{HP}$ electric pump, pressure tank and a concrete water tower, with a capacity of $30.6 \mathrm{cu}$. $\mathrm{m}$ which supplies the main laboratory, guest house, pilot laboratory, etc. with freshwater;

12. Saltwater system consisting of filtration and settling tank and a concrete saltwater tower which supplies filtered seawater to the hatchery tanks, the general biology laboratory, the reflecting pool, etc.

13. Hatchery Facilities with Prawn Tech. Plankton House and water system equipment.

(Jamias, Juan F. “A Brief History of the MSU-IFRD”. MSU-IRD Annual Report 1975. MSU-Institute of Fisheries Research and Development. Naawan, Misamis Oriental. 1975. p.144-145).

\subsection{Impact to Aquatic Industry}

Meanwhile, the study of DK Villaluz created a greater impact on the aquatic industry. Earlier fishpond operators in the country depended on unpredictable fry stock produced in nature and caught from the sea. With the discovery, there would be more or less stable supply of fry that could be mass produced at will almost throughout the year. Consequently, artificially produced fry could now compete equally with those collected from their natural habitat in terms of survival and growth rate and production cost. In addition, fishpond owners can be assured of a more or less uniform stock at the right time of seeding in their pond system. The study showed that the sugpo, PenaeusmonodonFabricius could be cultivated successfully in controlled enclosures. However, the only source of basic stocks was the sea. Hence, fishpond operators needed to go out and bring in juveniles that were produced naturally from the sea. The breakthrough inspired other institutions and private sectors in recent years to put up commercial hatcheries and, thus, provided bright prospects for a new dollar earning aquatic industry. It also attracted national and international linkages to pick on laboratory as the center for the coordination and integration of the studies and research activities in marine, brackish water and freshwater resources.

\subsection{The Establishment of School of Marine Fisheries and Technology}

On February 9, 1981, pursuant to Board of Regents Resolution No. 2190, S.1980, the creation of School of Marine Fisheries and Technology (SMFT). It was under the joint program of Mindanao State University -College of Fisheries and Mindanao State University -Institute of Fisheries Research and Development was approved. The School served as the academic arm of the Institute (BOR Resolution No. 2190. Series 1980. Office of the University Secretary. (February 9, 1981).

The school offer baccalaureate degree courses in marine fisheries and biology, and technology courses major in aquaculture and fish processing. The School operates on the concept of participatory management. The Dean of the College of Fisheries generally supervises its academic programs while the Director of MSU-Institute of Fisheries 
Research and Development oversees the administrative and external affairs. The execution of the functions and responsibilities is made mutually reinforcing through the policy of constant consultation. On the other hand, the College of Fisheries assigns the necessary faculty to handle the curricular offerings of the program and provides faculty honoraria, textbooks and reference materials for students and faculty. Campaign for student recruitment was done through radio broadcast, posters, billboards and communication.

Other activities such as recruitment or detail of faculty and administrative staff, procurement of laboratory equipment, supplies, reference materials and preparation of course syllabi by faculty involved in the Program are carried out by the MSU-IFRD (School of Marine Fisheries and Technology. "A Joint Program of the MSU-College of Fisheries and MSU-Institute of Fisheries Research and Development". 1980. pp.5-11.).

The contributions of DK Villaluz in research studies spun the creation of Mindanao State University at Naawan as an autonomous unit of Mindanao State University System by virtue of an Executive Order (EO 45) signed by former President Corazon C. Aquino and, later, by an action of the Board of Regents Resolution No. 92, S. 1988 upon the approved of MSU System Code of Governance. Mindanao State University at Naawan was reorganized following the triad function of the University. The research function of the unit was handled by the Institute of Fisheries Research and Development (IFRD), the extension service activities were managed by the Fisheries Technology Resource Center (FTRC), and the academic programs were implemented by the School of Marine Fisheries and Technology (SMFT) (Office of the Dean of IFRD. "Brief History". MSU-Naawan Annual Report 2004. (January 2004 to December 2004, p.2).

From then on, MSU at Naawan has accomplished the following: in research, it has completed several projects that developed the culture of technology of different aquatic species. In extension, it continuous to train prawn hatchery and fishpond technicians, the majority of which now man multi-million private hatcheries and pond systems. It also provides training programs to fish farmers, house wives, out -of-school youth on various aspects in fish farming;In academic, it has produced professionals in aquaculture and fisheries and thus improved the pool of skilled manpower for the industry. Meanwhile, DK Villalluz retired from active government service on July 4, 1973. He left indelible footprints which others followed suit and triggered a surge of research activities in aquaculture not only in the Philippines but in other countries as well. More significantly, he had inspired many young people to pursue a career in fisheries and marine biology.

For his laudable contributions to the development of Philippine fishery, he was awarded with the Rizal Pro Patria award by the President of the Philippines in the Diamond Anniversary of the Department of Agriculture in October 1976. Other prestigious awards received by Dean Villalluz are the following: Gregorio Y. Zara Scientist Award from the Philippine Association for the Advancement of Science Development Board, 1974. Outstanding Service Award from the Philippine Federation of Fish Farm Producers, 1974; UP Alumni Award, UP Alumni Association , 1977; and Pantas Award, from Philippine Council for Agriculture and Resources Research (PCARR), 1979.

DK Villalluz died last April 28, 1986 in Angono, Rizal at the age of 77. He had nine children, all of whom had become successful professionals in their own field of specialization. His dream to become a doctor was fulfilled by his daughter, Edna. DK Villalluz is remembered in the academic community and in the fishery industry as a scientist, a fishery expert, an educator and an environmentalist. His colleagues, former students, and research assistants in numerous research projects always remember him to be quiet unassuming pioneer and a true leader in his field for turning the laboratory into a research unit and finally a renowned institution in the field of aquaculture, fisheries and marine sciences in MSU System.

\section{Conclusion and Recommendation}

DK Villaluz' studies made a breakthrough in fisheries industry and to academic sector. His contribution became the foundation of Mindanao State University at Naawan to be the home of top caliber researchers in marine science and aquaculture education. This is due to brilliant and dedicated man who conscientiously worked for the interdependence and the relationships among forestry, agriculture and fishery. However, a call for a more critical approach to the leadership skills of DK Villaluz must be recommended for extensive findings.

\section{References}

Barros, A., Carneiro, A. and Wanderley, S. (2019), "Organizational archives and historical narratives: Practicing reflexivity in (re)constructing the past from memories and silences", Qualitative Research in Organizations and Management, Vol. 14 No. 3, pp. 280-294. https://doi.org/10.1108/QROM-01-2018-1604.

Carlyle, Thomas. (1841). On Heroes, Hero-Worship, and The Heroic in History. London, (Lecture 1).

Gill, Michael \& Gill, David \&Roulet, Thomas. (2017). Constructing Trustworthy Historical Narratives: Criteria, Principles, and Techniques. British Journal of Management. 10.1111/1467-8551.12262.

Gubin, A.V., Borzunov, D.Y., Marchenkova, L.O. et al. Contribution of G.A. Ilizarov to bone reconstruction: historical achievements and state of the art. StratTraum Limb Recon 11, 145-152 (2016). 
https://doi.org/10.1007/s11751-016-0261-7.

Keulen, S., \&Kroeze, R. (2012). Understanding management gurus and historical narratives: The benefits of a historic turn in management and organization studies. Management \& Organizational History, 7(2), 171189. https://doi.org/10.1177/1744935912438311.

Mohammed, Raed\&Nusari, Mohammed \&Ameen, Ali \&Alrajawy, Ibrahim. (2018). Leadership in the organization: A Conceptual Review. 2. 52-59.

Nasr, S. H. (2003). The achievements of IBN SINA in the field of science and his contributions to its philosophy. Islam \& Science, 1(2), 235.

Post, J. (Ed.). (2003). The Psychological Assessment of Political Leaders: With Profiles of Saddam Hussein and Bill Clinton. Ann Arbor: University of Michigan Press. Retrieved March 28, 2020, fromwww.jstor.org/stable/10.3998/mpub.11890.

Sergiovanni, Thomas J. and John E. Corbally (Eds). (1986). Leadership and Organizational Culture: New Perspectives of Administrative Theory and Practices. University of Illinois Press. Chapter 3. 